\title{
Physician Conceptions of Responsibility to Individual Patients and Distributive Justice in Health Care
}

Mary Catherine Beach, $M D, M P H^{1,2}$

Lisa S. Meredith, $P b D^{3}$

Kenneth B. Wells, MD, MPH',

Daniel E. Ford, MD, MPH ${ }^{1,2}$

'Division of General Internal Medicine, Johns Hopkins University School of

Medicine, Baltimore, Md

${ }^{2}$ Department of Health Policy and Management, Johns Hopkins University School of

Hygiene and Public Health, Baltimore, Md

${ }^{3}$ RAND Corporation, Santa Monica, Calif

${ }^{4}$ Department of Community Health and

Human Development, University of

California, Berkeley, Calif

${ }^{5}$ Department of Psychiatry and Biobehavioral Sciences, UCLA School of Medicine, Los Angeles, Calif
Jodi Halpern, $M D, P b D^{4}$

\begin{abstract}
PURPOSE Physicians' values may be shifting under managed care, but there have been no empirical data to support this claim. We describe physician conceptions of responsibility to individual patients and distributive justice in health care, and explore whether these values are associated with type of managed care practice and professional satisfaction.
\end{abstract}

METHODS We mailed a questionnaire to 500 primary care physicians from 80 outpatient clinics in 11 managed care organizations (MCOs) who were participating in 4 studies designed to improve the quality of depression care in primary care.

RESULTS We received 414 responses (response rate 83\%). Twenty-eight percent of physicians strongly agreed that their main responsibility was to the individual patient rather than to society (strong sense of responsibility to individual patients). Physicians with a strong sense of responsibility to individual patients were older ( $43 \%$ of physicians older than 50 years reported a strong sense of responsibility to individual patients, compared with $26 \%$ of physicians aged 36 to 50 years, and $21 \%$ of physicians younger than 35 years, $P=.009$ ) and tended to practice in network- rather than staff-model MCOs (33\% of physicians in network-model MCOs reported a strong sense of responsibility to individual patients compared with $24 \%$ in staff-model MCOs, $P=.077$ ). Scores on a scale measuring egalitarian conceptions of distributive justice within the health care system were similar for physicians regardless of whether they reported a strong sense of responsibility to individual patients. When we controlled for physician and practice characteristics, physicians with a strong sense of responsibility to individual patients and physicians with higher scores on an egalitarian scale were more likely to be very satisfied overall with their practices (adjusted odds ratio $[A O R]=2.23,95 \%$ confidence interval $[\mathrm{Cl}], 1.11-4.49$, and $\mathrm{AOR}=1.18,95 \% \mathrm{Cl}, 1.09-1.29$, respectively).

CONCLUSIONS Physicians with a strong sense of responsibility to individual patients are older and less likely to practice in staff-model MCOs. Stronger commitment to an egalitarian health care system and a strong sense of responsibility to individual patients are independently associated with greater practice satisfaction among physicians. The impact of these values on patient care should be a priority for future research and the subject of professional education and debate.

Ann Fam Med 2005;3:53-59. DOI: 10.1370/afm.257.

\section{INTRODUCTION}

CORRESPONDING AUTHOR

Mary Catherine Beach, MD, MPH

Division of General Internal Medicine School of Medicine

Johns Hopkins University

2024 East Monument Street, Suite 2-500

Baltimore, MD 21287

mcbeach@jhmi.edu
$\mathrm{T}$ The tension between physicians' obligations to individual patients and their obligations to society has perhaps never been greater or more widely debated. ${ }^{1-22}$ As health care costs have dramatically increased, physicians have been called upon to control spending by withholding marginally beneficial therapy from patients. ${ }^{1-5}$ It is argued that escalating costs result in higher insurance premiums, which in turn result in fewer people having access to health care. Although physicians may 
have always adopted some societal responsibility (for example, in patient assessment for disability benefits or competence) ${ }_{1}^{13}$ physicians are now urged to take responsibility for societal interests in improving access to health care. By doing so, however, physicians may experience ethical conflict with respect to where their primary responsibility lies. To avoid this conflict, many have argued that physicians ought be responsible only to individual patients. ${ }^{6,7,15,17,20-21}$ At the extreme of this view, physicians have been found to deceive third party payers or manipulate reimbursement rules to secure payment for necessary patient care. ${ }^{23-25}$

The argument about whether physicians ought to withhold marginally beneficial services from some persons so that others have access to health care is fundamentally a debate about distributive justice. Theories of distributive justice describe methods to allocate goods in limited supply relative to demand, and there is considerable disagreement about how goods ought to be distributed. The United States is engaged in such a debate over allocation of health care resources, and there is discussion about whether our society ought to distribute health care equally (often termed an "egalitarian distribution of resources"), or at least provide all persons with basic health care.

We designed this study to explore the extent to which physicians have a sense of responsibility to individual patients and an egalitarian conception of distributive justice within the health care system, to determine the relations between and determinants of these values, and to examine the possible associations between these values and professional satisfaction.

\section{METHODS}

\section{Study Design and Population}

We analyzed a cross-sectional survey of primary care physicians affiliated with 1 of 11 different managed care organizations (MCOs). The MCOs were chosen for their willingness to participate in 1 of 4 separate studies collectively known as the Quality Improvement for Depression (QID) program, which was designed to evaluate the effectiveness of quality improvement strategies for the treatment of major depression in primary care. ${ }^{26,27}$ Each of the 4 studies recruited organizations with diversity in either geographic location, organizational structure, or patient ethnicity. The MCOs in the study operated as either network- or staff-model organizations. Staff-model MCOs were defined as practices with prospective budgeting in which most clinicians worked exclusively for a single integrated health care system. Network-model MCOs included solo or small-group practices linked through some kind of practice network, all of which negotiate contracts with several managed care plans. ${ }^{26}$
The final sample of 500 eligible clinicians was drawn from 80 different outpatient sites in 11 different MCOs across the United States. Eligible clinicians in each study identified themselves as internists, family physicians, physician assistants, or nurse practitioners and spent at least $50 \%$ of their time providing primary care in one of the practices from a participating MCO. A total of 414 separate clinicians (response rate $83 \%$ ) completed the questionnaire. In this study, we exclude the 42 nonphysician clinicians and focus on the 372 physicians.

\section{Survey Administration}

Confidential questionnaires that took approximately 20 minutes to complete were mailed twice to all participating clinicians in 1996. Nonrespondents were telephoned and encouraged to return the questionnaire. Depending on the study, some clinicians were rewarded with a small gift or monetary incentive. Further details on the design and administration of the study are published elsewhere. ${ }^{27}$

\section{Survey Content}

The clinician questionnaire elicited demographic characteristics (age, sex, race), background and training (specialty, years in practice), professional practices (number of hours per week in direct patient care), attitudes and practices toward the treatment of depression, professional values, and practice satisfaction. The items measuring professional values were separated from the items measuring satisfaction by several pages in the questionnaire.

For this study, we focused on 2 basic professional values - sense of responsibility to individual patients and egalitarian beliefs about distributive justice within the health care system - and on the relationship of these values to physician satisfaction. Items measuring the 2 professional values were based on previous work ${ }^{28}$ and were further developed with input from 2 focus groups of community physicians. In the questionnaire, 1 question pertained to physicians' sense of responsibility, and 3 items pertained to their beliefs about distributive justice in health care. We asked respondents to indicate their level of agreement (from strongly agree to strongly disagree) with the statements listed in Table 1 . We also asked respondents to indicate their level of satisfaction (from very satisfied to very unsatisfied) with the following aspects of their practice: quality of care they provided to patients, ability to serve the needs of the enrollees, professional autonomy, compensation, and overall practice.

\section{Analysis}

First, we used descriptive statistics to show the distribution of responses to the 4 items measuring physicians' professional values. We then dichotomized the 
Table 1. Distribution of Percentage of Physician Responses to Professional Values Items

\begin{tabular}{|c|c|c|c|c|c|}
\hline Item & $\begin{array}{l}\text { Strongly } \\
\text { Agree }\end{array}$ & Agree & Neutral & Disagree & $\begin{array}{l}\text { Strongly } \\
\text { Disagree }\end{array}$ \\
\hline \multicolumn{6}{|l|}{ Sense of responsibility to individual patients } \\
\hline $\begin{array}{l}\text { The physician's main responsibility is to each individual patient rather } \\
\text { than to society }\end{array}$ & 28 & 42 & 13 & 13 & 4 \\
\hline \multicolumn{6}{|l|}{ Egalitarian beliefs about distributive justice } \\
\hline $\begin{array}{l}\text { It is the responsibility of society to provide everyone with the best } \\
\text { available health care }\end{array}$ & 18 & 35 & 13 & 25 & 9 \\
\hline $\begin{array}{l}\text { Society should allow patients who are willing to pay more to purchase } \\
\text { more expensive treatments }\end{array}$ & 25 & 38 & 20 & 8 & 8 \\
\hline $\begin{array}{l}\text { It is unfair, in principle, for some people to have different health care } \\
\text { than others for the same problems }\end{array}$ & 18 & 29 & 20 & 23 & 9 \\
\hline
\end{tabular}

responses to the item measuring sense of responsibility to individual patients to compare "strongly agree" (strong sense of responsibility to individual patients) with all other responses. We used $\chi^{2}$ tests to evaluate differences in MCO type, age, sex, race, specialty, geographic region, and number of hours per week in direct patient care between physicians with and without a strong sense of responsibility to individual patients. We then used logistic regression to examine the independent effects of MCO type and physician age on the sense of responsibility to individual patients while controlling for other potential confounders.

To summarize egalitarian beliefs about distributive justice within the health care system, we developed an egalitarian scale that represents the sum of responses to the 3 distributive justice items (with the second item reversed), ranging from 3 (lowest commitment to an egalitarian conception of justice in health care) to 15 (highest commitment). Thus, a score of 9 on the egalitarian scale is the equivalent of responding "neither agree nor disagree" on all 3 items. The reliability coefficient for this 3 -item egalitarian scale was $\alpha=.60$, and the scale had a normal distribution based on the Shapiro-Wilk test $(z=-0.859, P$ $=.80)$. We used $t$ tests and analysis of variance to evaluate differences in egalitarian scores by MCO type, age sex, race, specialty, geographic region, and number of hours per week spent in direct patient care. We then used linear regression to examine the independent effects of these variables on egalitarian scores.

Next, we sought to determine whether having a strong sense of responsibility to individual patients and strong egalitarian beliefs is related to physician satisfaction. We dichotomized each of the practice satisfaction measures between "very satisfied" and all other responses. We used $\chi^{2}$ tests to compare the percentage of "very satisfied" physicians with or without a strong sense of responsibility to individual patients on each specific satisfaction measure and on an overall physician practice satisfaction item. We then used logistic regression to assess the independent effects of having a strong sense of responsibility to individual patients and higher egalitarian scores on overall physician practice satisfaction while adjusting for potential confounders.

We also performed several subsidiary analyses. We explored the effect of choosing a different cutoff by repeating all analyses after redefining the "sense of responsibility to individual patients" to include all "strongly agree" and "agree" categories. We also tested for a potential interaction between MCO type and a strong sense of responsibility to individual patients by stratifying our analysis to examine whether the effect of having a strong sense of responsibility to patients on practice satisfaction was the same in network- and staff-model MCOs. All data were analyzed using Stata Version 6.0, and all analyses were adjusted for the clustering of physicians within managed care organizations.

\section{RESULTS}

\section{Characteristics of Physician Sample}

Most of the 372 physicians were male (67\%) and white $(68 \%)$, with a mean age of 43 years (range 26 to 76 years). Almost one half ( $48 \%$ ) of respondents were general internists, 39\% were family physicians, and $13 \%$ were still in training. One half of the physicians (51\%) were affiliated with a staff-model MCO and one half $(49 \%)$ were affiliated with a network-model MCO. The distribution of responses to the professional values items are shown in Table 1 . There were no significant differences in the mean egalitarian scores of physicians with or without a strong sense of responsibility to individual patients.

\section{Characteristics of Physicians With a Strong Sense of Responsibility to Individual Patients}

Physicians reporting a strong sense of responsibility to individual patients were older and tended to practice in network-model compared with staff-model MCOs 


\begin{tabular}{|c|c|c|c|c|c|}
\hline $\begin{array}{l}\text { Physician } \\
\text { Characteristic }\end{array}$ & No. & $\begin{array}{l}\text { Percent Reporting } \\
\text { Strong Sense of } \\
\text { Responsibility to } \\
\text { Individual Patients }\end{array}$ & $\begin{array}{c}P \\
\text { Value* }\end{array}$ & $\begin{array}{c}\text { Mean } \\
\text { Egalitarian } \\
\text { Score }\end{array}$ & $\begin{array}{c}P \\
\text { Value }^{\dagger}\end{array}$ \\
\hline \multicolumn{6}{|l|}{ Type of MCO } \\
\hline Staff model & 184 & 24 & & 8.89 & \\
\hline Network model & 188 & 33 & .077 & 8.86 & .932 \\
\hline \multicolumn{6}{|l|}{ Age, years } \\
\hline$<35$ & 76 & 21 & & 8.89 & \\
\hline $35-50$ & 224 & 26 & & 8.84 & \\
\hline$>50$ & 72 & 43 & .010 & 8.97 & .950 \\
\hline \multicolumn{6}{|l|}{ Sex } \\
\hline Male & 246 & 29 & & 8.55 & \\
\hline Female & 121 & 26 & .491 & 9.61 & .001 \\
\hline \multicolumn{6}{|l|}{ Race } \\
\hline White & 235 & 28 & & 8.70 & \\
\hline Nonwhite & 105 & 29 & .804 & 9.32 & .031 \\
\hline \multicolumn{6}{|l|}{ Type of provider } \\
\hline Family medicine & 138 & 31 & & 8.83 & \\
\hline Internal medicine & 172 & 30 & & 9.01 & \\
\hline Housestaff & 48 & 18 & .215 & 8.88 & .858 \\
\hline \multicolumn{6}{|l|}{ Geographic region } \\
\hline West & 237 & 26 & & 8.93 & \\
\hline Non-West & 135 & 33 & .154 & 8.79 & .651 \\
\hline \multicolumn{6}{|l|}{$\begin{array}{l}\text { Hours per week } \\
\text { direct patient care }\end{array}$} \\
\hline$<28$ & 74 & 25 & & 8.53 & \\
\hline $28-40$ & 181 & 27 & & 8.96 & \\
\hline$>40$ & 56 & 40 & .144 & 8.82 & .541 \\
\hline \multicolumn{6}{|c|}{ MCO = managed care organization } \\
\hline $\begin{array}{l}\text { * Obtained with } x^{2} \text { tests } \\
\dagger \text { Obtained with } t \text { tests } \mathrm{c}\end{array}$ & $\begin{array}{l}\text { omparin } \\
\text { d analysis }\end{array}$ & $\begin{array}{l}\text { rcentage of physicians } \\
\text { lariance, comparing me }\end{array}$ & $\begin{array}{l}\text { idividual } \\
\text { alitarian }\end{array}$ & ent ethic. & \\
\hline
\end{tabular}

(Table 2). There were no significant differences in sex, race, specialty, geographic region, or hours in direct patient care. After adjustment for number of hours per week in direct patient care, geographic region, and clustering of physicians within MCOs, physicians from staff-model MCOs and younger physicians had significantly lower odds of reporting a strong sense of responsibility to individual patients (Table 3 ). The intraclass correlation coefficient for the sense of responsibility to individual patients at the organization level was low $(0.03,95 \%$ CI, 0.00-0.07). Additional adjustment for physician sex, race, or specialty did not substantively change the results.

\section{Characteristics of Physicians With Stronger Egalitarian Beliefs}

The mean egalitarian scores associated with each physician demographic and practice characteristic are also presented in Table 2. Female physicians and nonwhite physicians had significantly higher egalitarian scores than male and white physicians, respectively. Both sex and race remained inde-

Table 3. Adjusted Odds of Physician Reporting Strong Sense of Responsibility to Individual Patients

\begin{tabular}{|c|c|c|}
\hline Factor & AOR* & $95 \% \mathrm{Cl}$ \\
\hline \multicolumn{3}{|l|}{ Type of MCO } \\
\hline Network model & 1.00 & \\
\hline Staff model & 0.67 & $0.51-0.88$ \\
\hline \multicolumn{3}{|l|}{ Age, years } \\
\hline$<35$ & 1.00 & \\
\hline $35-50$ & 1.48 & $0.73-2.97$ \\
\hline$>50$ & 3.30 & $1.38-7.93$ \\
\hline $\begin{array}{l}\text { Number of hours direct } \\
\text { patient care }\end{array}$ & 1.02 & $1.00-1.03$ \\
\hline \multicolumn{3}{|l|}{ Geographic region } \\
\hline Non-West & 1.00 & \\
\hline West & 0.77 & $0.60-0.98$ \\
\hline \multicolumn{3}{|c|}{$\begin{array}{l}\mathrm{AOR}=\text { adjusted odds ratio; } \mathrm{Cl}=\text { confidence interval; } \mathrm{MCO}=\text { managed care } \\
\text { organization. }\end{array}$} \\
\hline \multicolumn{3}{|c|}{$\begin{array}{l}\text { * Logistic regression model included MCO type, physician age, number of hours } \\
\text { in direct patient care, and geographic region. }\end{array}$} \\
\hline
\end{tabular}
pendently associated with egalitarian score after adjustment in linear regression analyses. The intraclass correlation coefficient for the egalitarian score at the organization level was low $(0.00,95 \% \mathrm{CI}, 0.00-0.03)$. There were no significant associations between egalitarian scores and physician age, specialty, MCO type, geographic region, or number of hours per week in direct patient care.

\section{Relations Between Professional Values and Satisfaction}

Without adjustment for physician and practice characteristics, physicians with a strong sense of responsibility to individual patients were significantly more likely to report being very satisfied with the quality of care they provided and with their ability to serve the needs of the enrollees (Table 4). There were no significant associations between sense of responsibility to individual patients and physician satisfaction with their professional autonomy, with their compensation, or with their overall practice. 


\begin{tabular}{|c|c|c|c|c|}
\hline $\begin{array}{l}\text { Specific } \\
\text { Satisfaction } \\
\text { Measure }\end{array}$ & $\begin{array}{l}\text { Physician } \\
\text { Response }\end{array}$ & No. & $\begin{array}{l}\text { Percent Reporting } \\
\text { Strong Sense of } \\
\text { Responsibility to } \\
\text { Individual Patients }\end{array}$ & $\begin{array}{c}\text { Mean } \\
\text { Egalitarian } \\
\text { Score }\end{array}$ \\
\hline \multirow{2}{*}{$\begin{array}{l}\text { Quality of care } \\
\text { provided }\end{array}$} & Very satisfied & 82 & 44 & 9.28 \\
\hline & Not very satisfied & 254 & $23^{*}$ & 8.79 \\
\hline \multirow{2}{*}{$\begin{array}{l}\text { Ability to serve } \\
\text { enrollee needs }\end{array}$} & Very satisfied & 54 & 48 & 9.23 \\
\hline & Not very satisfied & 280 & $24^{*}$ & 8.85 \\
\hline \multirow{2}{*}{$\begin{array}{l}\text { Professional } \\
\text { autonomy }\end{array}$} & Very satisfied & 52 & 31 & 9.15 \\
\hline & Not very satisfied & 281 & 28 & 8.83 \\
\hline \multirow[t]{2}{*}{ Compensation } & Very satisfied & 34 & 24 & 9.76 \\
\hline & Not very satisfied & 301 & 29 & $8.81^{\dagger}$ \\
\hline \multirow[t]{2}{*}{ Overall practice } & Very satisfied & 52 & 37 & 9.67 \\
\hline & Not very satisfied & 281 & 27 & $8.73^{+}$ \\
\hline
\end{tabular}

and almost one fifth either disagreed or strongly disagreed. Furthermore, although one might expect physicians' strong sense of responsibility to individual patients to be negatively correlated with strong egalitarian beliefs about the health care system, these values appear empirically to be independent. Finally, we found that both a strong sense of responsibility to individual patients and strong egalitarian beliefs about the health care system are associated with greater professional satisfaction among physicians. Each of these findings deserves separate consideration.

In our study, physicians with

A different pattern emerged for the relation between professional satisfaction and having an egalitarian conception of distributive justice in health care (Table 4). Whereas there were no significant associations between egalitarian beliefs and satisfaction with quality of care, ability to serve enrollee needs, or professional autonomy, there was a significant association between strong egalitarian beliefs and satisfaction with compensation and with overall practice. After adjustment for physician age, sex, race, number of hours per week in direct patient care, geographic region, and clustering of physicians within MCOs (Table 5), physicians reporting a strong sense of responsibility to individual patients, those with higher egalitarian scores, and those in network-model MCOs were significantly more satisfied with their overall practice.

When we redefined responses to the responsibility to individual patients to include all "strongly agree" and "agree" responses, physician age and MCO type remained significantly associated with sense of responsibility, but we found no association with physician satisfaction, suggesting that higher physician satisfaction may be related only to strong sense of responsibility to individual patients. We did not find an interaction between MCO type and sense of responsibility to individual patients on physician satisfaction.

\section{DISCUSSION}

Our study is the first to describe physicians' attitudes toward their responsibility to individual patients (vs society) and their egalitarian beliefs about health care. Although physicians generally agreed that their main responsibility was to each individual patient, we found that less than one third of PCPs strongly agreed a strong sense of responsibility to individual patients did not have significantly lower levels of commitment to strong egalitarian beliefs than physicians without a strong sense of responsibility. This finding may seem surprising, considering that undivided commitment

\begin{tabular}{|c|c|c|}
\hline Factor & AOR* & $95 \% \mathrm{Cl}$ \\
\hline \multicolumn{3}{|l|}{$\begin{array}{l}\text { Strong sense of responsibility } \\
\text { to individual patients }\end{array}$} \\
\hline No & 1.00 & \\
\hline Yes & 2.23 & $1.11-4.49$ \\
\hline Egalitarian score & 1.19 & $1.09-1.29$ \\
\hline \multicolumn{3}{|l|}{ Type of MCO } \\
\hline Network model & 1.00 & \\
\hline Staff model & 0.28 & $0.11-0.75$ \\
\hline \multicolumn{3}{|l|}{ Age, years } \\
\hline$<35$ & 1.00 & \\
\hline $35-50$ & 0.97 & $0.34-2.80$ \\
\hline$>50$ & 1.02 & $0.40-2.62$ \\
\hline \multicolumn{3}{|l|}{ Sex } \\
\hline Male & 1.00 & \\
\hline Female & 0.70 & $0.37-1.34$ \\
\hline \multicolumn{3}{|l|}{ Race } \\
\hline White & 1.00 & \\
\hline Nonwhite & 0.83 & $0.36-1.95$ \\
\hline $\begin{array}{l}\text { Noumber of hours in direct } \\
\text { patient care }\end{array}$ & 0.99 & $0.97-1.01$ \\
\hline \multicolumn{3}{|l|}{ Geographic region } \\
\hline Non-West & 1.00 & \\
\hline West & 1.89 & $0.75-4.78$ \\
\hline
\end{tabular}


to patients is thought by some to undermine egalitarian goals. ${ }^{1-5}$ These data suggest that physicians may not view strong responsibility to patients as opposed to egalitarian beliefs about distributive justice within health care. Responsibility to patients might be thought of as the responsibility of physicians, whereas a just distribution of resources might be thought of as the responsibility of society, which is reflected in the wording of the items. It may be that many physicians see both patient advocacy and just distribution of resources as morally desirable, although many have argued that these views are contradictory or unrealistic. ${ }^{1-5}$

Our study also found that physicians with a strong sense of responsibility to individual patients and physicians with stronger commitment to an egalitarian distribution of health care were more satisfied with their practices overall. This finding was true in both staffand network-model MCOs. These results add to our understanding of how physicians' values relate to their professional satisfaction and are important for those concerned with physician burnout and turnover. Recent studies have identified relationships with patients to be an important dimension of physician professional satisfaction. ${ }^{29-30}$ Previous work has shown that physicians who rate benevolence as the guiding principle in their lives reported higher career satisfaction, ${ }^{31}$ and that physicians who are given financial incentives to limit patient care are less satisfied with their careers. ${ }^{32}$ These data together suggest either that depth of moral commitment may play a role in determining physician satisfaction, or that physicians who are very satisfied with their work are better able to have such commitments, whether it is the belief in a strong social mission or caring deeply about the individual patient. Alternatively, there could be unmeasured confounding factors (such as personality or background) that account for both erosion of professional satisfaction and these different values. These issues are important to attend to more systematically in research and professional debate.

We also found that physicians with a strong sense of responsibility to individual patients are more satisfied with the quality of care they are able to give to patients and with their ability to serve the needs of the enrollees Further research is needed to determine whether physicians with a strong sense of responsibility to individual patients actually provide higher quality or more costly care or have higher patient satisfaction ratings.

Finally, we found that physicians in staff-model MCOs were less likely to report a strong sense of responsibility to individual patients than physicians in network-model MCOs. Several hypotheses may be put forth to explain this finding. One explanation might be that physicians choose a type of practice consistent with their underlying values. Physicians who choose to work in staff-model MCOs may be more accepting of the managed care approach, whereas those who choose financially independent group practices may be more individually oriented in their values. Alternatively, physicians' values may be influenced by their practice environment. If so, staff-model MCOs may be more effective at indoctrinating physicians to adopt a population-based ethic. Physicians in staff-model MCOs may be more likely to view resources as finite and therefore believe that money saved in caring for one patient will be applied to other patients. Alternatively, if physicians in staff-model MCOs are under greater pressure to control costs, then perhaps they adopt an ethic that allows them to do so without experiencing cognitive dissonance. Finally, there could be unobserved confounding factors that account for both these different values and type of managed care practice.

Our results possess several limitations. First, the items used in this questionnaire may need refinement. For example, some who disagreed that it is the responsibility of society to provide everyone with the best available health care could argue that society should provide everyone with the same basic level of health care, not the best health care. The reliability coefficient of the egalitarian scale was modest, although reliability coefficients of this magnitude are typical for scales addressing physician attitudes with only 3 or 4 items. ${ }^{33}$ Also, there was only 1 item used to measure the sense of responsibility to individual patients, although the wording of the item does seem to capture the essence of the concept. Further studies should focus on improving measurement of these important physician values.

Second, we are unable to assess cohort effects or causality with this cross-sectional data, yet we believe that our results highlight previously unexplored associations that should be further investigated. Third, these data are limited to a sample of primary care physicians from selected MCOs who may have different values than other primary care physicians or than subspecialists or surgeons. Although staff-model MCOs are becoming less common (thus limiting the generalizability of the findings related to MCO type), physicians affiliated with network-model MCOs are situated in a wide variety of practice settings and are representative of primary care physicians. As primary care physicians in MCOs have been given the role of gatekeepers, ${ }^{34}$ they seem to be a particularly important group to study. Fourth, these surveys were conducted in 1996, and physician opinions on these issues may have since changed. Lastly, although physicians with a strong sense of responsibility to individual patients work longer hours and were more likely to report satisfaction with the quality of care they give, we were not able to assess the quality of patient care directly. 
Exploration of physicians' core values is critical to deepening our understanding of the specific attitudes and behaviors that result from these underlying commitments. Our study has explored 2 important professional values, shown that physicians' values can be associated with their managed care environment, and shown that both having a strong sense of responsibility to individual patients and strong commitment to an egalitarian conception of justice are related to physicians' professional satisfaction. Further research is needed to understand fully the reasons for and consequences of these findings.

To read or post commentaries in response to this article, see it online at http://www.annfammed.org/cgi/content/full/3/1/53.

Key words: Professional practice; attitudes; personal satisfaction; ethics

Submitted September 25, 2003; submitted, revised, May 19 2004; accepted May 292004.

Portions of this work were presented at the annual meeting of the Society for General Internal Medicine, Date, 2002, Atlanta, Georgia.

Funding support: This work was supported by grants from the National Institute of Mental Health (U01-MH54443, U01-MH54444, U01MH50732, and P01-MH54623) and the Agency for Healthcare Policy and Research (R01-HS08349). Dr. Beach was a Greenwall Fellow in Bioethics and Health Policy while conducting this work.

\section{References}

1. Ubel PA, Arnold RM. The unbearable rightness of bedside rationing: physician duties in a climate of cost containment. Arch Intern Med. 1995; 155:1837-1842.

2. Khushf G. The case for managed care: reappraising medical and socio-political ideals. J Med Philos. 1999;24:415-433.

3. Minogue B. The two fundamental duties of the physician. Acad Med. 2000;75:431-442.

4. Morrheim H. Cost containment: challenging fidelity and justice. Hastings Cent Rep. 1988;18:20-25.

5. Hall MA. Rationing healthcare at the bedside. NY Univ Law Rev. 1994;69:693-780.

6. Kassirer JP. Managing Care - should we adopt a new ethic? New Engl J Med. 1998;339:397-398.

7. Kassirer JP. Our endangered integrity - it can only get worse. New Engl J Med. 1997;336:1666-1667

8. Carson RA. Balancing loyalties or splitting the difference? Acad Med. 2000;75:443-444.

9. Benson JA. The burdens of professionalism: patients' rights and societal justice. The Pharos. 2000;4-9.

10. Daniels N. The ideal advocate and limited resources. Theoret Med. 1987;8:69-80.

11. Menzel PT. Double agency and the ethics of rationing healthcare: a response to Martha Angell. Kennedy Inst Ethics J. 1993;3:287-292.

12. Daniels N. Why saying no to patients in the United States is so hard: cost containment, justice and provider autonomy. New Engl J Med. 1986:314:1380-1383.
13. Bloche MG. Clinical loyalties and the social purposes of medicine JAMA. 1999;281:268-274.

14. La Puma J, Cassel CK, Humphrey H. Ethics, economics, and endocarditis: the physicians' role in resource allocation. Arch Intern Med. 1988; 148:1809-1811.

15. Sulmasy DP. Physicians, cost control, and ethics. Ann Int Med. 1992; 116:920-926.

16. Sackett DL. The doctor's (ethical and economic) dilemma. A description of the dilemmas faced by a physician who tries to serve both individual patients and society. Office of Health Economics Annual Lecture 1996, London, England

17. Dyer AR. Patients, not costs, come first. Hastings Cent Rep. 1986;16:5-7.

18. Emanuel EJ, Dubler NN. Preserving the physician-patient relationship in the era of managed care. JAMA. 1995;273:323-329.

19. Crawshaw R, Rogers DE, Pellegrino ED, et al. Patient- physician covenant. JAMA. 1995;273:1553.

20. Angell M. Cost containment and the physician. JAMA. 1985;254: 1203-1207.

21. Angell M. The doctor as double agent. Kennedy Inst Ethics J. 1993; 3:279-286.

22. Daniels N. Justice, fair procedures, and the goals of medicine. Hastings Cent Rep. 1996;26:10-12.

23. Wynia MK, Cummins DS, VanGeest JB, Wilson IB. Physician manipulation of reimbursement rules for patients: between a rock and a hard place. JAMA. 2000;283:1858-1865.

24. Novack DH, Detering BJ, Arnold R, Forrow L, Ladinsky M, Pezzullo JC. Physicians' attitudes toward using deception to resolve difficult ethical problems. JAMA. 1989;261:2980-2985.

25. Freeman VG, Rathore SS, Weinfurt KP, Schulman KA, Sulmasy DP. Lying for patients: physician deception of third- party payers. Arch Intern Med. 1999;159:2263-2270.

26. Meredith LS, Rubenstein LV, Rost KM, et al. Treating depression in staff model vs. network model managed care organizations. J Gen Intern Med. 1999;14:39-48

27. Rost KM, Duan N, Rubenstein LV, et al. The Quality Improvement for Depression Collaboration: general analytic strategies for a coordinated study of quality improvement in depression care. Gen Hosp Psychiatry. 2001;23:239-253.

28. Colombotos J, Kirchner C. Physicians and Social Change. New York NY: Oxford University Press; 1986.

29. Konrad TR, Williams ES, Linzer M, et al. Measuring physician job satisfaction in a changing workplace and a challenging environment. SGIM Career Satisfaction Study Group. Society of General Internal Medicine. Med Care. 1999;37:1174-1182.

30. Linzer M, Konrad TR, Douglas J, et al, for the SGIM Career Satisfaction Study Group. Managed care, time pressure, and physician job satisfaction: results from the physician worklife study. J Gen Intern Med. 2000:15:441-450.

31. Eliason BC, Guse C, Gottlieb MS. Personal values of family physicians, practice satisfaction and service to the underserved. Arch Fam Med. 2000;9:228-232.

32. Hadley J, Mitchell JM, Sulmasy DP, Bloche MG. Perceived financial incentives, HMO market penetration and physicians' practice styles and satisfaction. Health Serv Res. 1999;34:307-321.

33. Meredith LS, Wells KB, Kaplan S, Mazel RM. Counseling typically provided for depression. Role of clinician specialty and payment system. Arch Gen Psychiatry. 1996;53:905-912.

34. Martin DP, Diehr P, Price KF, Richardson WC. Effect of a gatekeeper plan on health services use and charges: a randomized trial. Am J Public Health. 1989;79:1628-1632. 